\title{
Acessibilidade: visita técnica a três dos melhores restaurantes de Natal, Rio Grande do Norte, Brasil
}

\section{Accessibility: Technical visit to three of the best restaurants of Natal, Rio Grande do Norte, Brazil}

\author{
Carliane Ileicy da Silva (SILVA, I. C.) ${ }^{*} \mathrm{e}$ \\ Sérgio Rodrigues Leal (LEAL, S. R.) ${ }^{* *}$
}

\begin{abstract}
RESUMO - A falta de acessibilidade em infraestrutura e de capacitação de recursos humanos é uma das principais barreiras do direito de ir e vir com autonomia e dignidade das pessoas com deficiência. Os equipamentos de alimentação estão entre os equipamentos turísticos mais procurados e utilizados tanto pelos turistas como pelas populações autóctones. Com base nesses fatos, o objetivo desse trabalho foi o de analisar, no contexto do turismo inclusivo, se três dos melhores empreendimentos gastronômicos da cidade do Natal atendiam aos padrões de estrutura física e prestação de serviços necessários para o público de pessoas com deficiência. Para tal, utilizando-se do método de observação participante, foram realizadas visitas técnicas nos três restaurantes escolhidos. Os resultados mostraram que os restaurantes estudados cumpriam a maioria das exigências legais no tocante à acessibilidade. No entanto, com exceção de um dos restaurantes, apresentaram problemas na qualidade e adequação do serviço prestado às pessoas com deficiências.
\end{abstract}

Palavras-chave: Turismo; Restaurantes; Acessibilidade; Turismo inclusivo.

ABSTRACT - The lack of accessibility in infrastructure and human resources qualification are the main barriers to the right of coming and going with autonomy and dignity of people with any disability. Gastronomic facilities are amongst the most used tourism equipment and are used by both tourists and local population. Based on these facts, the aim of this study was to analyze, in the context of inclusive tourism, if three of the best gastronomic business enterprises in Natal meet the required standards of physical infrastructure and customer services for the segment of people with any disability. In order to do it, was adopted the observant participation technique, with technical visits in the three selected restaurants. The results showed that these three restaurants attend the majority of the legal requirements regarding accessibility. However, with exception of one of the restaurants, the other two presented problems with the quality and adaptation of the services for people with any disability.

Key words: Tourism; Restaurants; Accessibility; Inclusive Tourism.

\footnotetext{
"Graduação em Turismo pela Universidade Federal do Rio Grande do Norte (UFRN). Guest Relations (Rifoles Praia Hotel e Resort). Endereço: Rua Cel. Inácio Vale, 8847. CEP: 59.090-040 - Natal - RN (Brasil). Telefone: (84) 8881-7917. E-mail: liane_cis@ hotmail.com ou carlianeturismo@yahoo.com.br

** Graduação em Turismo e MBA em Administração de Marketing de Serviços pela Universidade Federal de Pernambuco (UFPE). Mestrado em Turismo pela Universidade James Cook (Austrália). Doutorado em Turismo pela Universidade de Surrey (Reino Unido). Professor Adjunto I da Universidade Federal do Rio Grande do Norte - Departamento de Turismo e Programa de Pós-Graduação em Turismo (UFRN). Endereço: Universidade Federal do Rio Grande do Norte - Departamento de Turismo (Campus Lagoa Nova). CEP: 59.072-970 - Natal - RN (Brasil). Telefax: (84) 3215-3535. E-mail: sleal@ufrnet.br ou sergiorleal@yahoo.com
} 


\section{INTRODUÇÃO}

Para suprir a necessidade do lazer, o indivíduo tem que satisfazer outras necessidades básicas, seja na sua cidade de origem, seja no período em que está praticando o turismo, como utilização dos serviços de saúde, segurança, acomodação e alimentação. Kotler (2000, p. 33) ressalta essa informação ao afirmar que as necessidades descrevem exigências humanas básicas (comida, ar, água, roupa), mas as pessoas também têm necessidades significativas de recreação, educação e entretenimento, que se transformam em desejos quando são dirigidas a objetos específicos capazes de satisfazê-las. Um tipo de equipamento que faz parte do turismo e é indispensável para a satisfação da necessidade de alimentação dos turistas são os equipamentos de alimentação. Vale ressaltar que os restaurantes, além de estarem entre os itens mais importantes das necessidades humanas básicas, também vêm sendo muito utilizados para agregar valor e atrair mais turistas aos destinos (SCHLÜTER, 2003; SOARES, 2008).

Os equipamentos de alimentação vêm se adequando e inovando para atender com qualidade o público que procura seus serviços, pois, a cada década, mais pessoas estão tentando a oportunidade de realizar atividades turísticas. Um dos grupos que vêm ganhando maior destaque nos últimos anos é o das pessoas com deficiências (PcD's) (FEITOSA, 2009).

Com a mudança de comportamento das PcD's em relação ao cumprimento das leis que trazem o direito de ir e vir, as empresas estão tendo que se adaptar e, com isso, o atendimento às pessoas com deficiência vem crescendo no Brasil, sobretudo após a promulgação da Constituição Federal de 1988. Com os direitos garantidos constitucionalmente, foram surgindo leis e medidas governamentais, que se somaram a ações da sociedade civil, na promoção de igualdade e de oportunidade às pessoas com deficiência no que tange ao acesso a educação, saúde, trabalho e lazer. Entre esses direitos, está o do acesso ao lazer e ao turismo, que pressupõe um conjunto de medidas de adaptação de forma a garantir o acesso com segurança e autonomia, total ou assistida, pelo público em questão. Tais modificações devem ser feitas com base na Norma Brasileira 9050 (ABNT, 2004), norma que rege as adequações necessárias para o público das PcD's (FEITOSA, 2009; TORRES, 2006; BRASIL, 2006a). A presente 
pesquisa foi baseada, principalmente, nos padrões estipulados pela NBR 9050 (ABNT, 2004) em três dos restaurantes mais visitados da cidade de Natal, assim classificados de acordo com a revista Veja Natal (2010/2011), que realiza processos seletivos e premiadores. Além da revista, foi utilizada uma pesquisa acadêmica sobre turismo e oferta alimentar (SOARES, 2008), que traz os restaurantes mais visitados da cidade de Natal. Com base nas informações oferecidas por essas fontes secundárias, os empreendimentos gastronômicos estudados foram selecionados e são apresentados no texto como "Restaurante A", "Restaurante B" e "Restaurante C", uma vez que não foi solicitada autorização para divulgação dos seus nomes.

A importância do tema turismo e acessibilidade pode ser evidenciada pelas várias pesquisas, várias instituições e diversos países do mundo que investem tempo e dinheiro em torno deste assunto. Dentre tais organizações estão a The Society for Accessible Travel and Hospitality (SATH), a Tourisme et Handicaps, o Ministério do Turismo, de forma indireta, e muitas outras. Apesar de existirem diversas pesquisas sobre turismo e acessibilidade, são poucas ou quase inexistentes pesquisas focadas na acessibilidade nos empreendimentos gastronômicos e, mais especificamente, em restaurantes de Natal.

Diante do exposto, esse artigo buscou analisar, no contexto do turismo inclusivo, se três dos melhores empreendimentos gastronômicos da cidade do Natal estavam aptos a oferecer uma estrutura física e de prestação de serviço satisfatórias para as pessoas com deficiência, de acordo com as normas existentes.

\section{GASTRONOMIA E TURISMO}

Os equipamentos de alimentação são de grande importância para um destino turístico, pois eles, muitas vezes, representam muito mais do que um simples espaço para alimentação. Nestes equipamentos, o consumidor-turista pode apreciar os pratos que representam o local, ouvir uma boa música; o turista pode contemplar produtos artesanais, tanto comestíveis como decorativos, que marcam a cultura do destino, além de ter a oportunidade de se deliciar com o encontro com amigos, parentes, 
acompanhantes ou até mesmo com alguém que conheceu há pouco tempo no próprio local onde está passando um determinado período (BAKER, 2003).

Os equipamentos de alimentação já têm sua importância destacada por uma instituição bem reconhecida, o Instituto Brasileiro de Geografia e Estatística - IBGE, que menciona que, dentre as atividades de bens e serviços, consumidos pelos turistas nacionais e internacionais numa determinada localidade receptora, destacam-se o alojamento, o transporte, a alimentação e o entretenimento. Pode ser dito que esses são considerados partes fundamentais e características do turismo. Os serviços de alimentação foram responsáveis pela maior parcela da receita, salários, pessoal ocupado e número de empresas em 2007 (IBGE, 2007).

Segundo a Secretaria de Turismo do Rio Grande do Norte, nos últimos anos, o setor de alimentação cresceu muito no estado. Natal possuía, em 2002, 1.173 equipamentos de alimentação, que geravam 5.238 empregos fixos diretos, 26.190 indiretos e 388 temporários (SETUR/RN, 2002). No entanto, não se sabe ao certo se este crescimento aconteceu devido ao aumento da população ou do desenvolvimento do turismo na cidade.

\section{PESSOAS COM DEFICIÊNCIA E TURISMO}

Existe um conjunto de cinco elementos - atrativo, infraestrutura, serviços, comunidade e turista (BRASIL, 2009b) - que cria um ambiente que pode ser chamado de "atmosfera do turismo". Cada qual exerce seu papel fundamental para que a atividade turística se desenvolva com equilíbrio, gerando benefícios em todos os âmbitos do turismo sustentável. A ausência de qualquer um destes elementos prejudica o desempenho do outro.

As pessoas com deficiência também fazem parte dessa atmosfera, pois elas podem compor o elemento comunidade ou o elemento turista. Além disso, as PcD's podem fazer uso dos outros elementos, como os serviços. Podem, ainda, ser prestadores de serviços turísticos. A evidência dessa utilização e participação na atividade turística pode ser vista em Buhalis et al. (2005), que discorrem que a demanda por acessibilidade no continente europeu é de mais de 127 milhões de pessoas, sendo que 89 milhões delas representam um potencial no mercado de consumo de produtos turísticos. 
Nos Estados Unidos, de acordo com Zografopoulos (2005), quase 70\% dos adultos com deficiência viajaram pelo menos uma vez nos últimos dois anos e, dentro desses $70 \%$, há um subgrupo que representa $20 \%$ que viaja, pelo menos, seis vezes a cada dois anos. $\mathrm{O}$ autor elucida também que americanos adultos com deficiência gastam U\$13,6 bilhões com viagens todo ano e, desse total, U\$2,7 bilhões são gastos em alimentos e bebidas (SHIMOZACAI, 2010).

\subsection{TURISMO ACESSÍVEL}

O turismo acessível, segundo Ferrés (2006), pode ser definido como uma iniciativa que visa incluir a maior parte possível da população naquelas atividades consideradas genericamente de turismo e/ou lazer. A autora comenta ainda que tal atividade também pode ser nomeada como Turismo para Todos. Para a implementação de um turismo acessível é necessário que se promova o processo de inclusão social, que acontece quando a sociedade é ajudada a modificar seus sistemas de lazer e turismo para que todas as pessoas, com ou sem deficiência, possam participar juntas e ativamente de suas atividades nos mesmos locais, desfrutando de momentos de lazer em ambientes comuns (SASSAKI, 2003).

A Constituição Brasileira afirma que toda pessoa com deficiência deve ter as mesmas oportunidades e alcançar a sua independência social e econômica para integrarse plenamente na sociedade, como parte de um processo em defesa da cidadania e do direito à inclusão social da pessoa com deficiência (BRASIL, 1988). O Governo Federal (BRASIL, 2009b, p. 16) corrobora com o Programa de Ação Mundial para Pessoas Portadoras de Deficiência das Nações Unidas, afirmando que:

\footnotetext{
Os países membros [da ONU] devem garantir que pessoas com deficiência tenham as mesmas oportunidades de desfrutar de atividades recreativas que têm os outros cidadãos. Isto envolve a possibilidade de freqüentar restaurantes, cinemas, teatros, bibliotecas, etc., assim como locais de lazer, estádios esportivos, hotéis, praias e outros lugares de recreação. Os países membros devem tomar a iniciativa removendo todos os obstáculos neste sentido. As autoridades de turismo, as agências de viagens, organizações voluntárias e outras envolvidas na organização de atividades recreativas ou oportunidades de viagem devem oferecer serviços a todos e não discriminar as pessoas com deficiência.
} 
Com base em alguns conceitos de turismo acessível (BRASIL, 2006b; TORRES, 2006; FEITOSA, 2009), chega-se à definição de que é uma atividade que possibilita a pessoa com deficiência alcançar e utilizar, com segurança e autonomia, edificações e equipamentos de interesse turístico.

\subsection{ADAPTAÇÕES FÍSICAS}

Para atender esse público é necessário que algumas modificações sejam realizadas nos empreendimentos. No caso dos restaurantes, as adaptações que devem existir são (ABNT, 2004; BRASIL, 2006a):

- 5\% do total do restaurante deve ser acessível à pessoa usuária de cadeira de rodas e ter sobre ela o símbolo internacional de acesso, SIA;

- Utilização do SIA nas entradas, nos estacionamentos, nos banheiros, nas saídas de emergência e em locais onde existem equipamentos exclusivos para pessoas com deficiência;

- Aplicação de sinalização tátil no piso, que pode ser do tipo alerta (com bolinhas em alto relevo) ou direcional (com linhas em alto relevo). Ambas devem ter textura e cor contrastante com o piso adjacente e servem para orientar os deficientes visuais. Deve ser aplicada em rampas, escadas e em obstáculos suspensos;

- Existência de espaço suficiente para mobilidade, pelo menos em uma parte do empreendimento. Deve haver espaço suficiente para a locomoção em todos os sentidos e dando possibilidade de giro em $360^{\circ}$, como no caso dos cadeirantes. Os banheiros também devem oferecer essa facilidade de movimento;

- Na área de aproximação deve ser garantido o posicionamento frontal ou lateral do módulo de referência em relação ao objeto em que a pessoa com deficiência deseja ter acesso. Além disso, são necessárias cadeiras confortáveis e com tamanhos diferentes do padrão para que todos tenham um bom acesso;

- Instalação de rampas de acesso nos principais pontos do restaurante, como por exemplo, na entrada.

- Os balcões de autosserviço (self-service) devem ter altura mínima de 0,8 m; e

- A edificação deve oferecer pelo menos um sanitário adaptado unissex. 
De fato, é necessário que os arquitetos, gestores e donos de estabelecimentos comerciais, como os restaurantes, estejam cientes dos tipos de adaptações que existem para que estudem e apliquem as melhores medidas necessárias para que esses equipamentos se tornem lugares para todos.

\subsection{ETIQUETA NA PRESTAÇÃO DE SERVIÇO ÀS PESSOAS COM DEFICIÊNCIA EM RESTAURANTES}

Outro fator muito importante para a satisfação das pessoas com deficiência é a maneira com que estas são tratadas nos estabelecimentos. Então, inicia-se agora uma lista de instruções que devem ser utilizadas nos equipamentos de alimentação, pois colaboram para a satisfação e um atendimento correto e de qualidade (BRASIL, 2006a, 2009a).

- Atender diretamente a pessoa com deficiência, perguntando em que pode ajudá-la, comunicando-se direto com a PcD e não com o seu acompanhante, caso haja;

- Permitir a entrada do deficiente visual com o cão guia sem ter que levá-lo a um gerente, ou algo similar. Deve haver um lugar reservado para ele e para o animal e ambos devem ser tratados com naturalidade;

- Providenciar um cardápio impresso em Braille com o nome do prato, ingredientes utilizados no preparo e o preço;

- Oferecer o serviço de prioridade a esse público;

- Realizar a capacitação de pelo menos um funcionário para que ele saiba utilizar a língua brasileira dos sinais, LIBRAS. Na impossibilidade de uso dessa linguagem e na ausência de intérprete, o funcionário deve procurar utilizar recursos como a mímica, gestos, expressão corpóreo-facial, perguntar se o cliente faz leitura labial e continuar falando bem devagar e sempre de frente ao surdo. Além disso, a escrita é outra saída (frases curtas, objetivas e sem duplo sentido ou metáforas);

- Ao falar com uma pessoa em cadeira de rodas, procurar situar-se de frente e na mesma altura da pessoa, sentando-se, por exemplo;

- Nunca mexer no "material" do deficiente sem pedir a permissão do mesmo. Tais "materiais", como cadeira de rodas, bengalas, cão guia e etc., são como uma 
extensão do corpo deles. Então, deve-se sempre perguntar se pode movê-los ou retirálos para algum lugar, se for realmente necessário;

- Se um deficiente visual, cego, precisar de ajuda para se locomover dentro do restaurante, deve-se dar o braço para que ele possa acompanhar o movimento ou, ficando à sua frente, possibilitar que siga seus passos. Esta segunda técnica deve ser mais usada em casos de lugares estreitos. Além disso, deve-se manter uma comunicação verbal constante, avisando quais os obstáculos que vêm à frente. É importante que se fale em tom baixo, pois eles são cegos e não surdos. Sempre se deve avisar quando a prestação do serviço for finalizada e o atendente estiver se retirando;

- No caso do deficiente intelectual, deve-se falar de forma simples, tentando identificar o principal problema e adaptando a linguagem à dificuldade da $\mathrm{PcD}$. Caso necessário, deve-se falar bem devagar. Adolescentes e adultos não devem ser tratados como crianças, cada faixa etária deve ser atendida com atitudes que correspondam às suas respectivas idades;

- Quando o PcD tiver alguma “anomalia”, não se deve olhar fixamente para o diferente. Também é importante que não sejam feitas perguntas de como o fato ocorreu, como ele ficou assim. Caso ele queira se expressar, escute, mas não dê muita ênfase ao assunto.

Além das normas relacionadas à infraestrutura, as questões ligadas à qualidade da prestação de serviços também devem ser estudadas para melhor atender às pessoas com deficiência.

\section{PROCEDIMENTOS METODOLÓGICOS}

O método utilizado constitui-se de uma pesquisa de abordagem qualitativa, de natureza exploratório-descritiva, uma vez que, além de descrever as características dos atores que utilizaram os equipamentos estudados, também se buscou analisar as experiências dos mesmos. Além disso, buscou-se identificar se os restaurantes estavam satisfatórios em relação às normas técnicas e etiquetas na prestação de serviços para pessoas com deficiência (CHIZZOTTI, 2000; TOGNETTI, 2006; DENCKER, 1998). 
A amostragem foi a não probabilística, pois os pesquisadores selecionaram o que acreditavam ser a melhor amostra para o estudo. Esse tipo de escolha de elemento é chamado amostragem por julgamento (SILVA, 2005). A população-alvo foi constituída por pessoas maiores de 18 anos, que estavam à frente de uma instituição que atendia a deficientes. Além disso, elas também são pessoas com deficiência.

Como instrumento da pesquisa na primeira etapa foi escolhida a observação participante e disfarçada (MATTAR, 2001) para se melhor alcançar o objetivo proposto. Essa observação foi realizada através de uma visita técnica onde um grupo formado por três pessoas com deficiência utilizou e analisou a estrutura e os serviços prestados nos empreendimentos estudados.

Para a segunda etapa da pesquisa foi realizada uma segunda visita, essa apenas com os pesquisadores, para medição dos móveis e ambientes. Assim, as medidas auferidas foram comparadas com as medições existentes na NBR 9050 (ABNT, 2004), para chegar-se à conclusão de se as medidas desses locais estudados correspondiam às normas exigidas ou não.

A coleta de dados da primeira etapa foi realizada no dia 25 de abril de 2011. Cada integrante da equipe recebeu uma prancheta com um roteiro impresso do que deveria ser analisado. Durante o consumo e o período em que o grupo esteve no local tudo era observado. No entanto, apenas após a saída do estabelecimento o roteiro individual era respondido.

As visitas da segunda etapa foram realizadas no mês de maio. Para as medições, foi utilizada, além da fita métrica, uma lista com três colunas. Na primeira, havia todos os itens que deveriam ser medidos. Na segunda, as medidas exigidas pela NBR 9050 (ABNT, 2004). Por fim, na terceira, espaço em branco para a medição que foi auferida nos restaurantes.

\section{RESULTADOS}

Nesta seção, são apresentados os resultados da pesquisa de campo nos restaurantes A, B e C no tocante à infraestrutura física e à qualidade na prestação de serviços. Inicialmente, são apresentadas as características de cada empreendimento. 


\subsection{CARACTERIZAÇÃO DOS EMPREENDIMENTOS}

Os empreendimentos são caracterizados, apresentando informações sobre data de fundação e suas peculiaridades. Em seguida, cada restaurante é classificado de acordo com os critérios apresentados por Fonseca (2000) e Grimal e Serra (1997).

\subsubsection{Restaurante A}

O Restaurante A faz parte de uma rede que possui três restaurantes na cidade de Natal. No entanto, para este estudo, foi escolhida apenas uma unidade. O Restaurante A foi inaugurado no ano de 2005 (Site oficial do Restaurante A, 2010). Esse restaurante tem receitas internacionais e influência da culinária regional; possuindo um ambiente com decoração peculiar, elementos rústicos e típicos do nordeste brasileiro. Possui, também, carta de vinhos e um sommelier ${ }^{1}$. Portanto, é considerado um restaurante de tipo gastronômico (FONSECA, 2000; GRIMAL e SERRA, 1997).

\subsubsection{Restaurante B}

O Restaurante B foi fundado em 1990, em João Pessoa, e possui outras filiais, a utilizada para o estudo localiza-se em Natal. Esse restaurante tem sua estrutura rústica, a decoração é feita com lustres de fuxico ${ }^{2}$, colheres de pau e outros utensílios da roça que enfeitam das mesas ao teto. O sistema utilizado no empreendimento é o self-service e nele são ofertadas mais de 100 receitas, dentre elas, receitas originais e tradicionais (Site oficial do Restaurante B, 2010).

Analisando a estrutura e o modelo de serviço, pode-se afirmar que o Restaurante B se encaixa em duas classificações, tradicional e típico (FONSECA, 2000; GRIMAL e SERRA, 1997), isso porque, apesar de servir no modelo self-service, há uma variedade de comida, a decoração é de material simples e representa a cultura nordestina do Brasil.

\footnotetext{
${ }^{1}$ Profissional que estuda os tipos e estilos de vinho, regiões produtoras, serviço do vinho, define a carta de vinhos, administra a adega e, principalmente, harmoniza os vinhos com os pratos (RUSSO, 2009).

${ }^{2}$ É uma forma de artesanato que se utiliza de uma técnica que dobra e costura retalhos de panos em formato de flor (FUXIQUEIRA, 2006).
} 
Além disso, a especialidade é comida de tempero regional e o público é bem eclético (Site oficial do Restaurante B, 2010).

\subsubsection{Restaurante C}

Na cidade de Natal, há dois restaurantes desta mesma rede. No entanto, como objeto de estudo do presente trabalho, foi utilizada apenas uma filial, que está em funcionamento desde 1997. Como principal serviço tem o rodízio de carne e, à disposição dos clientes, existem 18 cortes e 100 opções de pratos quentes, boa parte regional (Site oficial do Restaurante C). A estrutura do lugar é rústica, lembrando e retratando as casas de taipa do interior. Assim, pode-se dizer que este restaurante está classificado como um Grill, porém não é de luxo, é tradicional, pois representa a cultura do nordeste (FONSECA, 2000; GRIMAL e SERRA, 1997).

\subsection{ESTRUTURA FÍSICA}

Nesta seção são apresentados os resultados referentes à infraestrutura dos restaurantes visitados. Os resultados foram alcançados através das medições realizadas nos restaurantes com base na NBR 9050 (ABNT, 2004).

\subsubsection{Sinalização}

Com relação à sinalização de placas, todos os três restaurantes a possuíam. Porém, estas não estavam presentes em todos os lugares necessários e nem todas seguiam os formatos estabelecidos pela NBR 9050 (ABNT, 2004). Já a aplicação de sinalização tátil, do tipo alerta e direcional, foi inexistente em todos restaurantes e em todos os lugares. O piso tátil não estava aplicado nem nos espaços mais necessários e exigidos, como nas rampas, nas escadas, em obstáculos suspensos, nas entradas, nas portas de elevadores, banheiros etc. 


\subsubsection{Estacionamento}

Verificou-se que, dos três restaurantes, o Restaurante A e o Restaurante B estavam mais preparados, já que neles foram encontrados estacionamentos onde constava o símbolo de acesso para pessoas com deficiência, tendo as demarcações diagonais e em amarelo. O espaço para estacionar apresentou-se dentro do padrão. No Restaurante B, por exemplo, identificou-se que a vaga tinha $2,56 \mathrm{~m}$ e a do Restaurante A tinha 2,66m. Além disso, as vagas dos dois restaurantes eram bem livres e sem obstáculos. Nesses dois restaurantes pode-se perceber que os estacionamentos foram bem planejados e concretizados, uma vez que o Restaurante B tinha um estacionamento bem amplo nos fundos, mas as vagas para pessoas com deficiência foram deixadas bem de frente à entrada. No Restaurante $\mathrm{A}$, a situação era parecida. Nele se constatou um estacionamento geral bem amplo de frente, porém do outro lado da rua, mas as vagas para pessoas com deficiências se posicionando na frente do restaurante e ficando temporariamente bloqueadas para que outros carros não as utilizem.

O único restaurante que não cumpriu os requisitos relacionados ao estacionamento foi o Restaurante $\mathrm{C}$, uma vez que, na frente do restaurante, o espaço da vaga não tinha as marcações corretas, ou seja, não tinha marcação horizontal, apenas um cavalete azul com o SIA. A vaga não possuía espaço suficiente, ela tinha 2,50m de largura, mas não oferecendo espaço para circulação, próxima de obstáculos, pequenos tocos de madeira que não possibilitam que uma pessoa com deficiência saia pelos dois lados, apenas por um, isso se não houver um carro estacionado do outro lado. No estacionamento lateral, as leis com relação à acessibilidade foram mais bem atendidas, pois a vaga tinha $2,95 \mathrm{~m}$ de largura, o símbolo estava um pouco apagado, mas estava na horizontal, na vertical não tinha uma placa, mas tinha um portão e lá estava o símbolo de acesso anexado.

\subsubsection{Calçadas, Rampas e Desníveis}

Foi visto que a calçada do Restaurante B estava dentro dos padrões, pois a

calçada era plana, sem obstáculos e não precisava de rampas de acesso, já que o estacionamento e a calçada que davam acesso ao restaurante estavam no mesmo nível 
da rua. Já a calçada do Restaurante C estava bem deteriorada, com buracos e itens decorativos que atrapalhavam a locomoção das pessoas com deficiência. Além disso, a calçada e o estacionamento ocupavam o mesmo espaço, e esses não eram retos, eram inclinados e possuíam alguns pontos ondulados. O Restaurante A também estava dentro dos padrões de acessibilidade com relação à calçada. Não havia a utilização de rampas de acesso, pois a vaga de estacionamento, calçada e entrada estavam no mesmo nível. $\mathrm{Na}$ borda da calçada existia o piso tátil de alerta, mas este se apresentando deteriorado em alguns pontos. Mesmo assim, pelo fato desses itens ocuparem o mesmo espaço, facilitavam a locomoção das pessoas com deficiência e com mobilidade reduzida.

\subsubsection{Espaços para Circulação e Mobiliário}

Nenhum dos três restaurantes reservou 5\% da área para pessoas com deficiência. No entanto, a própria arquitetura que cada um possui favorece até mais do que essa porcentagem com relação à área de acesso. No Restaurante B, por exemplo, a entrada tem 1,30m de largura, e grande parte do restaurante tem uma distância de $1,00 \mathrm{~m}$ entre uma mesa e outra; do tampo até o chão, a mesa tem $75 \mathrm{~cm}$ e o balcão de self-service é baixo. Já a parte de fechamento de conta não é tão acessível, a porta tem pouco menos de 1,20m, a maçaneta não é de alavanca e o balcão não é baixo, tendo mais de $1,20 \mathrm{~m}$ de altura. O encarregado pelo atendimento ao cliente do Restaurante B informou que nesses casos não é necessário que o cliente vá até a área de pagamento, um garçom fíca responsável por acompanhar e ajudar esse público. Apesar da ajuda, nesse caso, a autonomia foi perdida. Com relação ao piso, no geral, ele é plano, mas em alguns locais é formado de mosaicos, porém eles não impossibilitam a ida e vinda a certos pontos.

No Restaurante C também havia bastante espaço para circulação, 1,56m de uma mesa para outra nos corredores principais; as mesas, do tampo ao chão, tinham $82 \mathrm{~cm}$, mas o balcão de self-service era alto, passava de 1,00m, e o local de pagamento também não era acessível, era alto e fechado, de difícil acesso até para quem não tem deficiência. Pelo menos, com relação ao tamanho das entradas, esse restaurante não possui problema, já que as entradas são do tipo porteiras, ou seja, portões bem grandes. O piso desse restaurante em muitas partes estava deteriorado, ele possuía rachaduras que atrapalhavam tanto o deficiente visual como o cadeirante. $\mathrm{O}$ piso também não era 
homogêneo, a decoração trazia partes com mosaicos, tijolos e até "grelhas", o que dificultou o acesso em algumas partes.

No Restaurante A, o espaço de circulação de uma mesa para outra mediu 1,28m e a mesa $75 \mathrm{~cm}$ do tampo até o chão. A entrada era ampla, 1,85m, e os balcões que deveriam ter de $75 \mathrm{~cm}$ a $85 \mathrm{~cm}$, mediram mais de 1,00m. Entretanto, no caso desse restaurante, quase ninguém ia ao balcão pegar algo ou pagar a conta, quase tudo era levado à mesa, da comida à conta. No entanto, pelo menos uma parte deles deveria ter um rebaixamento. Já o piso era todo plano, a decoração não atrapalhava a locomoção. Mas, na entrada, há uma rampa que não atendia aos padrões, pois era de madeira e não possuía piso tátil. Apesar disso, ela não prejudicava o acesso ao restaurante pelo fato de ser larga $(1,89 \mathrm{~m})$, ser firme e não ser escorregadia.

\subsubsection{Banheiros}

De maneira geral, os banheiros se apresentaram bem para as pessoas com deficiência, pois no Restaurante $\mathrm{B}$, na entrada para o banheiro, havia uma placa com o SIA e com o Braile, tudo dentro dos padrões. A placa indicava que um dos banheiros, além de acessível, era unissex. Com relação às medidas, algumas foram atendidas de acordo com a ABNT e outras não. A porta, por exemplo, tinha $84 \mathrm{~cm}$, abria para fora e a maçaneta era em formato de barra de apoio, a bacia sanitária tinha $47 \mathrm{~cm}$ de altura, a torneira podia ser utilizada com movimentos fáceis, assim como a descarga. A papeleira possuía $52 \mathrm{~cm}$ e estava bem próxima do vaso e da pia. $\mathrm{O}$ banheiro tinha $1,70 \mathrm{~m}$ por $2,63 \mathrm{~m}$, permitindo uma manobra de $180^{\circ}$. O espelho não tinha inclinação de $10^{\circ}$, porém era bem rebaixado e possuía barras de apoio, além de estar bem localizado, ou seja, todos esses pontos dentro do padrão. Porém, a pia estava suspensa apenas $68 \mathrm{~cm}$, a fechadura não proporcionava movimentos fáceis para utilização e não possuía piso antiderrapante.

No Restaurante $\mathrm{C}$, ambos os banheiros, masculino e feminino, tinham na entrada uma placa com o SAI, porém esta não correspondia aos padrões da $\mathrm{ABNT}$, pois era de madeira, sem a cor azul e não possuía o Braile. Com relação aos quesitos que atenderam às normas, foi encontrada a porta com $86 \mathrm{~cm}$, a maçaneta em formato de alavanca, a bacia sanitária com $47 \mathrm{~cm}$ de altura, a torneira que podia ser utilizada com movimentos 
fáceis, assim como a descarga. As papeleiras possuíam $51 \mathrm{~cm}$, uma estava bem próxima do vaso e a outra da pia, que mediu $84 \mathrm{~cm}$. O banheiro tinha $1,75 \mathrm{~m}$ por $1,60 \mathrm{~m}$, permitindo manobra de $180^{\circ}$, possuía barras de apoio, além de estar bem localizado. Poucos itens não atenderam aos padrões de acessibilidade, dentre eles, a fechadura da porta que não proporcionava movimentos fáceis para utilização, não possuía piso antiderrapante, a porta abria para dentro e o espelho não era rebaixado o suficiente e não possuía $10^{\circ}$ de inclinação.

Analisando a estrutura do banheiro do Restaurante A, foram encontradas algumas irregularidades. O lavatório era muito alto, $90 \mathrm{~cm}$. Com essa altura, o fato da pia ser acionada por sensor não ajuda a PcD a utilizá-la. O espelho, na mesma situação, impossibilitava a visualização de uma pessoa com baixa estatura. A porta possuía 1,40m de largura. Os fatores positivos foram a sinalização correta azul e em Braile, permitia o giro de $180^{\circ}$, o vaso tinha $47 \mathrm{~cm}$, a papeleira estava próxima do vaso e tinha $80 \mathrm{~cm} \mathrm{de}$ altura, a porta abria para fora, a maçaneta era em formato de barra, existiam outras barras dentro da cabine e a descarga era fácil de manusear. Esse restaurante atualmente possui um banheiro masculino e feminino com cabines adaptadas para pessoas com deficiência, porém um banheiro unissex adaptado já está quase pronto para uso. Este está dentro de quase todas as normas, as medidas estão todas dentro dos padrões, da porta ao piso, só estava faltando a placa de SIA e a marcação em Braile.

\subsection{SERVIÇO PRESTADO}

Os três restaurantes possuíam cardápio em Braile. No entanto, o Restaurante B não oferecia o cardápio do buffet, apenas de ceia, lanches e bebidas. Além disso, o cardápio não ficava em fácil acesso e não era oferecido automaticamente. Foi preciso pedir o cardápio ao garçom. Quando o cardápio chegou à mesa foi perceptível que estava guardado há um tempo considerável pela quantidade de poeira que ainda havia nele. No buffet, também não havia placas em Braile. Se a PcD for sozinha, o garçom informou que eles acompanham o cliente e vão dizendo prato por prato.

No Restaurante C, o cardápio era completo, com todo o buffet, bebidas e valores. Porém, o mesmo era velho e manchado de algo amarelado como mancha de café. Além 
disso, mais uma vez, não foi oferecido o cardápio. Este foi requisitado pela equipe e não estava em local de fácil acesso como os outros cardápios.

Já no Restaurante A, o cardápio estava completo e bem organizado, novo, encadernado e limpo. Não foi preciso solicitar o cardápio. Assim que a equipe foi acomodada, ele foi levado à mesa.

Um resultado encontrado que não surpreendeu foi o fato de nenhum dos restaurantes possuírem pelo menos um funcionário que soubesse usar a língua dos sinais. Isso, apesar de existir uma lei que diz que todo equipamento deve oferecer interpretes ou pessoas capacitadas em LIBRAS (BRASIL, 2009a).

Com relação ao atendimento em si, puderam ser percebidas diversas reações por parte dos funcionários que atenderam a equipe. A principal percepção é que a atenção ou importância dada ao cliente se diferenciava de acordo com a deficiência que ele tinha.

Inicialmente, no Restaurante B, o atendimento ocorreu da seguinte forma: assim que a equipe chegou, os garçons demoraram a atender, não sabiam como agir; depois, quando de fato vieram atender e acomodar o grupo, dirigiram a atenção à pessoa que não tinha deficiência e ao integrante da equipe técnica que era cadeirante.

No Restaurante C, a princípio, um garçom começou o atendimento, mas, quando foi perguntado sobre o cardápio em Braile, chamou o maitre, que, em seguida, chamou o gerente. Esse foi bem educado e atencioso. Depois disso, o maitre voltou e continuou o atendimento bem naturalmente. No entanto, mesmo com a integrante cega estando com o cardápio em Braile na mão, mais uma vez, nada foi perguntado a ela nem ao "surdo-mudo".

O Restaurante A se destacou. Os funcionários ajudaram e atenderam de forma natural toda a equipe, abriram a porta do carro, perguntaram aos integrantes se precisavam de ajuda, logo em seguida ofereceram uma das melhores mesas. Para surpresa e satisfação da equipe, o restaurante possuía um elevador para pessoas com deficiência, um garçom coloca a pessoa no elevador na parte de baixo e outro recebe a pessoa no andar de cima, abrindo a porta e encaminhando-a para a melhor mesa disponível.

Neste restaurante, mais de um garçom atendia aos clientes, e o que veio buscar o pedido indagou a todos se os integrantes iriam fazer os pedidos juntos ou se cada um 
iria pedir um prato. Ou seja, de maneira simples ele envolveu todos os participantes da equipe. O garçom também perguntou individualmente o que cada um gostaria de beber. Por fim, serviu a todos e outro garçom foi até a mesa e, girando o corpo e a cabeça, perguntou a todos: "Desejam mais alguma coisa?".

\section{CONSIDERAÇÕES FINAIS}

É tão verdadeiro que os pensamentos da sociedade para com as pessoas com deficiência vêm se transformando, seja por espontânea vontade, seja por imposição da lei, que muitas são as pesquisas que surgiram buscando trazer melhorias e analisar os espaços e serviços utilizados por esse público. No contexto atual, não só as pessoas com deficiência lutam por um mundo mais igualitário, mas pessoas sem deficiências também buscam colaborar para uma sociedade e um turismo sem exclusão.

Foi buscando fazer parte desse grupo que luta por um turismo para todos que essa pesquisa trouxe como objetivo analisar, no contexto do turismo inclusivo, se três dos melhores empreendimentos gastronômicos da cidade do Natal estavam aptos a oferecer produtos e serviços satisfatórios para as pessoas com deficiência de acordo com a percepção desse público.

Com base em todo o processo realizado para conseguir atingir esse objetivo e tendo analisado os resultados encontrados, pode ser dito que o objetivo foi alcançado com sucesso. Mas, para alcançar esse objetivo, foi necessário um estudo sobre os padrões relacionados à estrutura e à escolha de uma técnica eficiente para atender os quesitos relacionados aos serviços prestados.

Apesar dos restaurantes terem sido escolhidos sob a classificação de "os melhores", o resultado encontrado foi inesperado, pois muitas leis referentes ao tema acessibilidade não são respeitadas. Com isso, imaginou-se que em Natal essa situação não seria diferente, até mesmo porque ela é uma cidade turisticamente "nova" se comparada a outros destinos mais consolidados. No entanto, os três restaurantes estudados superaram as expectativas do grupo que realizou a visita. Pois, os empreendimentos corresponderam a muitas das normas da NBR 9050 (ABNT, 2004), ou seja, se apresentaram como parcialmente acessíveis. 
Pelo que foi visto, a principal falha dos empreendimentos gastronômicos estava na falta de capacitação dos funcionários, pois nenhum deles usou a linguagem dos sinais e não sabia se portar perante o público de pessoas com deficiência. Então, a sugestão que fica é que esses empreendimentos, assim como outros, realizem cursos e palestras dentro da empresa para capacitar sua equipe, para que eles tenham o mínimo de conhecimento sobre esse público e para que saibam como melhor atendê-los para que não comentam gafes na "etiqueta" e para que não tornem um momento de prazer em um momento constrangedor. Além disso, é importante que as empresas encarem as mudanças como um investimento e não um gasto e, após a concretização das mudanças, essas devem ser divulgadas pelo restaurante, pois, assim, as pessoas com deficiência ficarão cientes dos lugares que podem utilizar com maior comodidade.

\section{REFERENCIAS}

ASSOCIAÇÃO BRASILEIRA DE NORMAS TÉCNICAS - ABNT. NBR 9050. Acessibilidade a edificações, mobiliário, espaços e equipamentos urbanos. Rio de Janeiro, 2004.

BAKER, A. F. A gastronomia e a sua integração com o turismo e a nutrição. 2003. 63 f. Monografia (Especialização em Qualidade em Alimentos) - Universidade de Brasília, Brasília, 2003.

BRASIL. Bem atender no turismo acessível. Brasília: Ministério do turismo, v. 3, 2009a.

BRASIL. Constituição da República Federativa do Brasil, 1988.

BRASIL. Turismo acessível: introdução a uma viagem de inclusão. Brasília: Ministério do Turismo, v. 1, 2009b.

BRASIL. Turismo e acessibilidade: manual de orientações. 2. ed. Brasília: Ministério do Turismo, 2006a.

BRASIL. Turismo social: diálogos do turismo uma viagem de inclusão. Rio de Janeiro: IBAM, 2006b.

BUHALIS, D.; EICHHORN, V.; MICHOPOULOU, E.; MILLAR, G. Accessibility market and stakeholder analysis: one stop shop for accessible tourism in Europe. Reino Unido: Universidade de Surrey, 2005. 
CAMBOIS, E. Disability and Social Participation in Europe. Eurostat, 2001.

CHIZZOTTI, A. Pesquisa em ciências humanas e sociais. 4. ed. São Paulo: Cortez, 2000 .

DENCKER, A. de F. M. Métodos e técnicas de pesquisa em turismo. São Paulo: Futura, 1998.

FEITOSA, A. R. Turismo e inclusão social: um estudo sobre as contribuições do marketing social para a inclusão das pessoas com deficiência no usufruto do turismo no Brasil. 2009.150f. Monografia (Graduação em Turismo) - Universidade Federal do Rio Grande do Norte, Natal/RN.

FERRES, S. P. Turismo acessível 2006. Disponível em: <http://styx.nied.unicamp.br:8080/todosnos/acessibilidade/textos/turismo_acessivel.htm 1>. Acesso em: 23/11/2011.

FONSECA, M. T. Tecnologias gerenciais de restaurantes. 2. ed. São Paulo: SENAC, 2000.

FUXIQUEIRA. $\quad$ O fuxico... $2006 . \quad$ Disponível em: <http://www.fuxiqueira.com/fuxico/>. Acesso em: 21/09/2011.

GRIMAL, J. B.; SERRA, R. V. Servicio de atencion al cliente en restauracion. Madri: Sintesis, 1997.

IBGE. Instituto Brasileiro de Geografia e Estatística. Pesquisa anual de serviços. Rio de Janeiro: v. 9, 2007.

KOTLER, P. Administração de marketing. Trad. Bázan Tecnologia e Lingüística. 2. ed. São Paulo: Prentice Hall, 2000.

MATTAR, F. N. Pesquisa de Marketing: edição compacta. São Paulo: Atlas, 2001.

RUSSO, D. Afinal o que é um sommelier, um enólogo e um enófilo?. 2009. Disponível em: <http://degustate.blogtv.uol.com.br/2009/04/01/afinal-o-que-e-umsommelier-um-enologo-e-um-enofilo>. Acesso em: 21/09/2011.

SASSAKI, R. K. Inclusão no lazer e turismo em busca da qualidade de vida. São Paulo: Áurea, 2003.

SCHLÜTER, R. G. Gastronomia e Turismo. São Paulo: Aleph, 2003.

SECRETARIA DO ESTADO DO RIO GRANDE DO NORTE - SETUR/RN. Perfil do Turismo no Rio Grande do Norte - Oferta de Equipamentos Turísticos, 2002. Natal: 2002. 
SHIMOSAKAI, R. Turismo adaptado. Disponível em: <http://turismoadaptado.zip.net/>. Acesso em: 25/03/2010.

SILVA, M. E. M. da. Qualidade como alavanca para o desenvolvimento do turismo. Caderno Virtual de Turismo, v. 5, n. 1, 2005.

SOARES, J. C. de M. Turismo e oferta alimentar: gostos e percepções dos turistas sobre os estabelecimentos de alimentação e a gastronomia em Natal/ RN. 2008. 124f. Monografia (Graduação em Turismo) - Universidade Federal do Rio Grande do Norte, Natal/RN.

TOGNETTI, M. A. T. R. Metodologia da pesquisa científica. Slides de apresentação. São Paulo: Serviço de Biblioteca e Informação do Instituto de Física de São Carlos IFSC, 2006. Disponível em: <http://sbiweb.if.sc.usp.br/metodologia_pesquisa_cientifica.pdf>. Acesso em: 24/09/2010.

TORRES, F. Guia de acessibilidade urbana edificações: fácil acesso para todos. Belo Horizonte: CREA, 2006.

VEJA NATAL, Comer e Beber 2010/2011. Restaurantes: as mesas campeãs. Disponível em: <http://vejabrasil.abril.com.br/natal/roteiro/restaurantes/as-mesascampeas-41/>. Acesso em: 21/09/2011.

ZOGRAFOPOLUS, K. Travelers with disabilities: the American market. Slides de apresentação Grécia, 2005. Disponível em: <www.ossate.org/library-news >. Acesso em: 10/04/2010.

Recebido em: 31-07-2011.

Aprovado em: 31-08-2011. 